\title{
Las formas de gobierno local tras cuarenta años de Ayuntamientos democráticos: evolución y retos
}

\section{Local government system after forty years of democratic councils: development and challenges}

\author{
Silvia Díez Sastre \\ Instituto de Derecho Local de la UAM (España) \\ ORCID: https://orcid.org/0000-0002-3101-0469 \\ silvia.diez@uam.es
}

\section{NOTA BIOGRÁFICA}

Profesora de Derecho Administrativo de la Universidad Autónoma de Madrid, desde diciembre de 2018 dirige el Instituto de Derecho Local de la misma Universidad (www.idluam.org) y su Máster en Contratación Pública Local. Asimismo, es directora del informe sobre justicia administrativa del Centro de Investigación sobre Justicia Administrativa de la UAM desde 2015 (www.cija-uam.org/informe). Sus líneas de investigación principales se centran en el Derecho local, el Derecho de la contratación pública, la justicia administrativa y la metodología jurídica.

\section{RESUMEN}

Desde la celebración de las primeras elecciones locales democráticas hace cuarenta años, la forma de gobierno local ha experimentado numerosos cambios. Algunos de ellos se enmarcan en corrientes de democratización y reforzamiento de los gobiernos locales que superan las fronteras nacionales; otros tienen que ver con la realización de ajustes en el marco del sistema territorial español. Todos ellos han consolidado un modelo exitoso de gobierno local que, no obstante, se enfrenta a numerosos retos en el futuro, tanto de carácter político y administrativo, como geográfico y demográfico. El presente trabajo realiza un recorrido por los principales hitos de esta evolución y trata de identificar cuáles pueden ser las líneas de discusión sobre la forma de gobierno local en el futuro.

\section{PALABRAS CLAVE}

Gobierno local; alcalde; concejales; autonomía local.

\begin{abstract}
Local government system has undergone many changes since the first local democratic election was held forty years ago. Some of these changes fall within waves of democratization and strengthening of local governments that go beyond national boundaries, whilst others relate to the implementation of certain adjustments within the Spanish territorial framework. All of the said changes have consolidated a successful local government model which nonetheless faces numerous political, administrative, geographical and demographic challenges. This paper looks into the various milestones of this local government development, and it tries to outline the future areas of debate regarding local government forms.
\end{abstract}

\section{KEYWORDS}

Local government; mayor; councillors; local self-government. 


\begin{abstract}
SUMARIO
INTRODUCCIÓN. 1. EJES DE EVOLUCIÓN DE LAS FORMAS DE GOBIERNO LOCAL. 1.1. EL GOBIERNO MUNICIPAL. 1.1.1. De corporaciones locales a gobiernos locales. 1.1.2. Parlamentarización del gobierno local. 1.1.3. Diversificación del gobierno local. 1.2. EL GOBIERNO PROVINCIAL. 2. ARRAIGO Y DESARROLLO DE LOS DERECHOS DE REPRESENTACIÓN POLÍTICA. 2.1. ACCESO A LA INFORMACIÓN. 2.2. DERECHOS ECONÓMICOS. 2.3. EL ESTATUTO DE LOS CONCEJALES NO ADSCRITOS. 3. RETOS DEL GOBIERNO LOCAL. 3.1. RETOS POLÍTICOS Y ADMINISTRATIVOS. 3.1.1. Profesionalización y separación de funciones. 3.1.2. Gobiernos en minoría. 3.1.3. Elección directa del alcalde. 3.2. RETOS GEOGRÁFICOS Y DEMOGRÁFICOS. 3.2.1. Eje rural-urbano. 3.2.2. Envejecimiento de la población. REFERENCIAS BIBLIOGRÁFICAS.
\end{abstract}

\title{
INTRODUCCIÓN ${ }^{1}$
}

Tras más de treinta años de dictadura franquista, el 3 de abril de 1979 se celebraron las primeras elecciones locales democráticas en España. Bajo la vigencia del texto constitucional de 1978, los vecinos de 7.870 municipios eligieron a 67.505 concejales, registrándose un $62,5 \%$ de participación. Desde entonces se han celebrado diez elecciones locales, las últimas el 26 de mayo de 2019. En 2019 celebramos, por tanto, cuarenta años de Ayuntamientos democráticos. Con ocasión de esta efeméride, a continuación, se analizan las formas del gobierno local en el Derecho español a partir de varios ejes de evolución, prestando especial atención a los retos que plantea el futuro, políticos y administrativos, de un lado, y demográficos y geográficos, de otro lado. No se trata de hacer una exposición y análisis exhaustivos de cada uno de los aspectos relevantes de las formas de gobierno local y de los cambios que han experimentado; sino de realizar un recorrido por los principales hitos de desarrollo de los gobiernos locales, tratando de identificar los posibles problemas que deberán hacerse frente en los próximos años.

Como punto de partida, hay que tener en cuenta que en el periodo anterior a la Constitución de 1978 no existían en puridad gobiernos locales. Los ayuntamientos se orientaban fundamentalmente a la ejecución de las normas de policía administrativa y no a la elaboración de políticas públicas. De modo que su composición y organización respondía a esa función. El alcalde se nombraba por el ministro de gobernación o el gobernador civil y los concejales eran elegidos mediante el llamado "sufragio orgánico»: por cabezas de familia, organizaciones sindicales y otros concejales (Caldero Cabré, 1998: 7).

La introducción de una forma de gobierno local conformada por órganos elegidos democráticamente supuso, en este contexto, un cambio radical que se proyectó, fundamentalmente, en dos direcciones: consolidando la legitimidad de las decisiones de política y administración local de los entes locales, así como desarrollando la autonomía local constitucionalmente garantizada (arts. 137, 140 y 141 CE) (Embid Irujo, 1981: 441 ss.). La consolidación de una dimensión política y no meramente administrativa de los entes locales constituye, así, un punto de inflexión en la configuración de las formas de gobierno local.

La Constitución de 1978 contiene dos garantías fundamentales que están inescindiblemente unidas: autonomía local -expresada genuinamente en la potestad de autoorganización (Parejo Alfonso, 1991: 21)y gobierno elegido democráticamente. De hecho, como ha puesto de manifiesto la doctrina, la autonomía local tuvo en el siglo XIX un mayor entronque con la configuración del poder democráticamente, que con la distribución del poder entre distintos niveles territoriales (Ortega Álvarez, 2011a: 271). De manera que las elecciones municipales de 1979 introdujeron dos elementos desconocidos hasta ese momento: objetivos políticos en la actividad municipal, ligados a los ámbitos de interés local, y legitimación democrática de las decisiones que adopten los órganos municipales (Calderó Cabré, 1998: 8).

Las garantías constitucionales no se prevén, sin embargo, por igual, para municipios y provincias. Mientras que en los municipios se garantiza la elección democrática directa de los concejales (art. 140 CE), no sucede lo mismo con las diputaciones provinciales, cuyos miembros tendrán carácter representativo (art. $141 \mathrm{CE}$ ). Como se apuntará más adelante, esta circunstancia ha sido y es determinante en el debate abierto sobre el papel de la provincia en el modelo territorial español. Además, en relación con los municipios el texto constitucional deja claro que habrá Ayuntamientos o Concejo Abierto -esto es, todos los vecinos constituirán

Este trabajo se enmarca en el Proyecto I+D, "Aging Cities (Ciudades Envejecidas)" de la convocatoria de Retos de 2016 del Ministerio de Economía, Industria y Competitividad, DER-2016-75987-R. 
la asamblea, entre cuyos miembros se elegirá a un alcalde (al respecto, Salanova Alcalde, 2011: 19 ss.)-; y que en las provincias el órgano de gobierno será en todo caso la Diputación.

El desarrollo de la regulación en torno al gobierno local con base en la Constitución se produjo años después de la mano de la Ley $7 / 1985$, de 2 de abril, reguladora de las Bases del Régimen Local (LBRL). Esta Ley, tomada como parámetro cuasi-constitucional por el Tribunal Constitucional en muchas ocasiones (Velasco Caballero, 2009: 171 ss.), partió de un concepto amplio de lo básico para regular la forma de gobierno local, garantizando la homogeneidad en todo el territorio. Desde entonces ha sido el eje del régimen local y, por tanto, de la regulación de la forma de gobierno local. Ahora bien, desde su aprobación en 1985 hasta 2019 ha sido objeto de numerosas reformas, algunas de las cuales se exponen seguidamente.

\section{EJES DE EVOLUCIÓN DE LAS FORMAS DE GOBIERNO LOCAL}

\subsection{El gobierno municipal}

En el ámbito municipal pueden identificarse tres ejes de evolución en torno a los cuales se pueden articular con facilidad las reformas acometidas en la forma de gobierno municipal -algunos de estos ejes también pueden verificarse en las tendencias de reforma del régimen local en los países de nuestro entorno-. El primero de ellos es el reconocimiento de los entes locales como verdaderos gobiernos locales; el segundo sería la tendencia a la parlamentarización progresiva del gobierno local; y el tercero se refiere a la introducción progresiva de una cierta diversificación de las formas de gobierno local.

\subsubsection{De corporaciones locales a gobiernos locales}

El hito más importante que experimentaron los municipios y el gobierno municipal tras la aprobación de la Constitución fue el reconocimiento de su dimensión política, más allá de su dimensión administrativa ligada, principalmente, a la prestación de servicios a su comunidad de vecinos. Como se ha señalado anteriormente, la garantía de autonomía local y la legitimidad democrática de los órganos de gobierno municipal contribuyeron a la aceptación de la trascendencia de sus decisiones en el plano político. Los municipios dejan de ser considerados meras corporaciones locales para ser gobiernos locales, actores en el sistema territorial por derecho propio (Font i Llovet, 2005: 17 ss.). Esta sustancia política de los entes locales no es incompatible con su posición distinta en el mapa territorial, en la medida en que no gozan de potestad legislativa (Salazar Benítez, 2007: 49 ss.). Las instituciones locales tienen carácter administrativo y que, al carecer de potestad legislativa, están ubicadas totalmente en el marco de la Ley (Parejo Alfonso, 2011: 68). Ahora bien, de la mera adopción de decisiones administrativas, técnicas, sobre la gestión de servicios, pasan a elaborar políticas públicas en la esfera de sus competencias, ampliada a través del concepto de autonomía local.

El desarrollo de la dimensión política de los entes locales inaugurada con las primeras elecciones democráticas discurrió en una primera fase por el camino de la atribución de una mayor capacidad de decisión política a los entes locales. Las reivindicaciones de los municipios cristalizaron en el denominado Pacto Lo$\mathrm{cal}$, que consistió en la reforma de varias leyes con el fin de reforzar a municipios y provincias. En concreto, por lo que respecta a la forma de gobierno local, se incluyó en la LBRL la posibilidad de crear grupos políticos en el Pleno municipal, de la mano de la Ley 11/1999; se reformó la LOREG mediante la Ley Orgánica 8/1999 para introducir la moción de censura y la cuestión de confianza a nivel local; y se diseñó el régimen de los municipios de gran población mediante la Ley 57/2003, de reforma de la LBRL. Esta corriente de reforma local, vinculada a la condición política de los gobiernos municipales, se enmarcó en la denominada segunda descentralización. Este proceso abrió un intenso debate en torno a la propia evolución del Estado que tuvo sus detractores (véase, por todos, Parada Vázquez, 2007: 2 ss.) y sus defensores (también, por todos, Font i Llovet, 2002: 14 ss.). Finalmente, los avances en el proceso se plasmaron en el Libro Blanco del Gobierno Local, que ponía de manifiesto la conveniencia de dotar de más autonomía y poder a los entes locales. Lo cierto es, sin embargo, que no se llevaron a cabo reformas de calado con posterioridad y se produjo un cambio en la línea de evolución del gobierno local. Las reformas tendentes a reforzar el carácter político de los entes locales dieron paso a un debate centrado en el modelo territorial, que tiene como protagonista fundamental a Cataluña.

En esta nueva línea puede hablarse de una segunda fase de desarrollo de los gobiernos locales relacionada con los Estatutos de Autonomía de segunda generación y que se ha identificado con la tendencia 
a la «interiorización» del régimen local (Font i Llovet, 2006). Esta corriente se incardina en una línea más amplia de evolución del modelo territorial hacia un sistema federal, que puede tener distintas dimensiones: como materia estatutaria, institucional, territorial y competencial (al respecto, en detalle, Galán Galán, 2010: 100 ss.). La propuesta que se realiza consiste en entender que el régimen local debe corresponder, fundamentalmente, al nivel territorial intermedio, autonómico, del mismo modo que sucede en los Estados federales, donde los entes locales son parte de la Administración de los Estados federados y no de la Federación. Con ocasión de la reforma de los Estatutos de Autonomía (Cataluña y Andalucía), se trataron de introducir cambios en este sentido. Las Sentencias del Tribunal Constitucional 247/2007 -relativa al Estatuto valenciano- y 31/2010 -referida al Estatuto catalán- admitieron la posibilidad de que los Estatutos de Autonomía regularan el régimen local, pero únicamente en lo relativo a las líneas fundamentales o regulación esencial. Estos pronunciamientos se han percibido por parte de la doctrina como una puerta abierta a la profundización en la interiorización del régimen local, especialmente en el contexto de Cataluña (Font i Llovet y Galán Galán, 2014: 36 ss.). Sin embargo, también hay interpretaciones que consideran que el fuerte arraigo de la estructura territorial en tres niveles ha hecho difícil y cuestionable la aceptación de estas tesis tanto en la mayoría de la doctrina, como en la jurisprudencia, especialmente (Pomed Sánchez, 2010: 74 ss.; Ortega Álvarez, 2011a: 270). Habrá que esperar para ver en que dirección continúa este debate.

\subsubsection{Parlamentarización del gobierno local}

El gobierno de los municipios en los que se entiende que no hay una dimensión política clara no requiere una distinción nítida de funciones normativas, ejecutivas y de control. Todos los miembros del gobierno toman parte en la adopción de decisiones, sin perjuicio de que el alcalde tenga una posición de cierto liderazgo y, sobre todo, de representación del municipio (Díez Sastre, 2010: 563). Este modelo no es compatible, por tanto, con el reconocimiento de autonomía local y de una dimensión política de los entes locales. En ese caso, es preciso realizar una atribución de competencias diferenciada entre los distintos órganos municipales. En esa línea, el modelo de la LBRL partía de una distinción de funciones entre alcalde y Pleno. El alcalde asume el impulso político y administrativo del municipio y es el órgano competente para adoptar la mayoría de las resoluciones administrativas. Por su parte, el Pleno asume el deber de controlar políticamente la actuación del alcalde, pero también adopta decisiones administrativas de especial importancia o trascendencia para el municipio (Parejo Alfonso, 2014: 15).

Este modelo de distribución de funciones evolucionó en el marco del denominado Pacto Local -al que se ha hecho referencia más arriba- a través de concretas reformas normativas: es el caso de la modificación de la LRBL mediante la Ley 57/2003, de medidas para la modernización del gobierno local, que introdujo el régimen de funcionamiento de los municipios de gran población; de la reforma de la LOREG con el fin de introducir la moción de censura y la cuestión de confianza en el ámbito local; así como de la modificación de la LOTC para regular los conflictos en defensa de la autonomía local. Todas estas reformas se incardinan en una tendencia a la denominada «parlamentarización» del gobierno local; y suponen un paso más en el reconocimiento de la dimensión política de los entes locales (Jiménez Asensio, 2003: 76 ss.; Ortega Álvarez, 2011b: 903) Esto significa que, en el reparto de funciones entre los órganos municipales, el Pleno pierde poder en la adopción de decisiones administrativas, pero refuerza su capacidad de control y de fiscalización del ejecutivo municipal. Además, se mantiene como el órgano que ejerce la potestad normativa a nivel municipal. Por su parte, el alcalde refuerza su liderazgo y capacidad de dirección de la política municipal. Desde el punto de vista del funcionamiento de los órganos, también el Pleno se asemeja más a las cámaras parlamentarias, haciendo preceptivas las comisiones informativas.

Ahora bien, aunque ciertamente pueden encontrarse semejanzas entre el funcionamiento del modelo parlamentario y el modelo de gobierno local diseñado tras estas reformas normativas, lo cierto es que subsisten diferencias de importante calado, que impiden realizar una identificación entre las formas de gobierno a nivel estatal y autonómico, de un lado, y local, de otro lado (Salazar Benítez, 2007: 113 ss.). Al no tener atribuida potestad legislativa, no existe una relación entre ejecutivo y legislativo articulada en torno a las dos dimensiones del principio de legalidad: reserva de Ley y principio de primacía de la Ley. Además, el Pleno continúa ostentando potestades propias de la Administración. Existe un modelo de distribución legal de poder entre los órganos municipales que no se apoya en la jerarquía de uno frente a otros, sino en el principio de competencia (Velasco Caballero y Díez Sastre, 2008: 49 ss.). La traslación del modelo parlamentario al nivel de gobierno local presenta, por tanto, límites estructurales. 
En la línea de la parlamentarización del gobierno local, la Ley 57/2003, de medidas para la modernización del gobierno local, introdujo en la LBRL la posibilidad de que formaran parte de la Junta de Gobierno Local miembros que no ostentaran la condición de concejales, siempre que su número no superara el tercio de sus miembros, excluido el alcalde (art. 126.2 LBRL). Esta reforma trataba de permitir una mayor diversidad en la configuración de los órganos de gobierno locales como sucede en el Derecho comparado, con gerentes profesionales al frente de las ciudades. Por ejemplo, en Italia se admite que el alcalde nombre y revoque a los miembros de su equipo de gobierno, incluyendo a ciudadanos que no forman parte del Pleno (Medina Alcoz, 2010: 235). Esta opción, sin embargo, se declaró inconstitucional por la STC 103/2013. Consideró entonces el Tribunal Constitucional que la Constitución reserva el gobierno municipal al alcalde y a los concejales elegidos por los ciudadanos (art. $140 \mathrm{CE}$ ), impidiendo que se incorporen otros miembros. El texto constitucional impone, a su juicio, la elección democrática de los integrantes del gobierno local. La Sentencia contó con dos votos particulares en los que se ponían de manifiesto las dudas sobre la posible vulneración de la autonomía municipal al hacer una interpretación tan restrictiva del precepto constitucional. Sin embargo, el resultado es una importante homogeneidad en la composición y forma de los gobiernos locales.

\subsubsection{Diversificación del gobierno local}

La LBRL estableció un modelo de bases densas, que tendía a la homogeneidad en la estructura del gobierno local en la mayor parte de los municipios -con la salvaguarda del modelo de concejo abierto-. De acuerdo con la STC 214/1989, la organización local está estructurada en dos niveles: básica o necesaria (correspondiente a la legislación del Estado) y complementaria (atribuida a las Comunidades Autónomas) (Fernández Farreres, 2011: 1.493). La regulación básica se concibió de forma minuciosa para los órganos esenciales de gobierno, tanto de los municipios como de las provincias. En consecuencia, se estrechó el margen disponible para que las Comunidades Autónomas establecieran una regulación complementaria, conforme a lo previsto en los artículos 20.2 y 32.3 LBRL (Fuertes, 1991: 171 ss.; Sánchez Morón, 2011: 372); y, lógicamente, se dejó muy poco espacio para los reglamentos orgánicos que quedan vinculados por lo establecido tanto en la LBRL como en la regulación autonómica complementaria (Sánchez Morón, 2011: 373; Fernández Farreres, 2011: 1.481 ss.).

De modo que lo habitual en el modelo español de régimen local ha sido que el gobierno local tuviera la misma estructura en todo el territorio, con independencia de las características de los distintos gobiernos locales a lo largo del territorio. Esta tendencia se rompió gracias a la reforma de la LBRL mediante la Ley $57 / 2003$, de medidas para la modernización del gobierno local, que estableció diferencias organizativas entre los municipios de «régimen común» y los municipios «de gran población». La ruptura de la homogeneidad fue bienvenida; sin embargo, no tuvo como efecto la apertura de un mayor margen de decisión autonómico o local en torno a la organización municipal. Siguiendo la tradición consolidada a lo largo de los años, el legislador estatal estableció una regulación exhaustiva de la organización municipal, más detallada incluso que en el caso de los municipios de régimen común (Sánchez Morón, 2011: 372). La Ley dejaba poco margen de desarrollo tanto a las Comunidades Autónomas como a los propios municipios (de forma crítica, Jiménez Asensio, 2003: 74) y ello ha dado problemas en su implementación por los municipios debido a la dificultad que supone cumplir con todas las exigencias legales (al respecto, en detalle, Carbonell Porras, 2009).

En la misma línea de ruptura de la homogeneidad de la forma de gobierno local, hay que situar a los regímenes locales de carta, que afectan fundamentalmente a Madrid y Barcelona; aunque también hay que tener en cuenta a las ciudades autónomas de Ceuta y Melilla (Ortega Álvarez, 2011c: 1.622 ss.). En el caso de Madrid, el régimen especial deriva de su condición de capital del Estado (art. $5 \mathrm{CE}$ ). Además, el Estatuto de Autonomía de Madrid (art. 6) reconoce la posibilidad de que exista un régimen especial para la villa de Madrid (Ortega Álvarez, 2011c: 1.620). De manera que en 2006 se aprobó la Ley de Capitalidad junto al régimen de la especialidad de Madrid como gran municipio (Ley 22/2006, de 4 de julio, de capitalidad y régimen especial de Madrid). En el caso de Barcelona, también existe un régimen ad hoc que se contiene en dos normas legislativas, de la Generalitat de Catalunya, por un lado (Ley 22/1998, de 30 de diciembre, de la Carta Municipal de Barcelona), y del Estado, por otro lado (Ley 1/2006, de 13 de marzo, por la que se regula el régimen especial del municipio de Barcelona). De este modo se atiende a las particularidades de esta gran ciudad (en detalle, Cases Pallarés, 2008: 81 ss.). En ambos casos se establecen regímenes de carta, específicos, pero no por ello son modelos más abiertos. En la práctica, tanto Madrid como Barcelona tienen poco margen para optar o desarrollar un modo de organización distinta o una forma de gobierno local distinta de la prevista legalmente. 


\subsection{El gobierno provincial}

La estructura de los órganos de gobierno de las provincias ha solido tratarse como un derivado de la organización municipal; de forma que es posible encontrar numerosos paralelismos con los municipios (Morell Ocaña: 2011: 1.591). A esta situación coadyuva el hecho de que los diputados provinciales no se elijan directamente por los ciudadanos, sino que se elijan de forma indirecta a partir de los resultados de las elecciones municipales. Esto puede explicar que no se haya prestado tanta atención a la forma de gobierno provincial de forma autónoma y también puede explicar la mayor debilidad de las provincias en el mapa local. Su legitimidad democrática de segundo nivel ha jugado en contra de la justificación de su existencia.

En este sentido, hay que tener en cuenta que, en el régimen local español, el cuestionamiento de la existencia y forma de organización de las provincias ha sido una constante desde la confirmación de la STC 32/1981 de la autonomía provincial con ocasión de la impugnación de la Ley catalana 6/1980 (al respecto, Santamaría Pastor, 1982: págs. 179 ss.). Ese cuestionamiento se ha generalizado en la última década con la apertura de un intenso debate sobre la posible abolición y reforma de las provincias en el contexto de la crisis económica (al respecto, Cosculluela Montaner, 2011: 63 ss.) y sobre la necesidad de flexibilizar el nivel intermedio de gobierno local (Font i Llovet y Galán Galán, 2014: 28 ss.). Esta discusión entronca con otras medidas de redimensionamiento de la planta local que han acontecido en los países de nuestro entorno (sobre estas reformas, Almeida Cerreda, 2015: 29 ss.) y puede decirse que es una discusión que todavía permanece abierta (Barrero Rodríguez, 2017: 315 ss.; Tajadura Tejada, 2019: 229 ss.). La reforma operada por Ley 27/2013, de 27 de diciembre, de racionalización y sostenibilidad de la Administración Local (LRSAL) no parece haber aplacado las críticas sobre la configuración de las provincias en el sistema territorial.

\section{ARRAIGO Y DESARROLLO DE LOS DERECHOS DE REPRESENTACIÓN POLÍTICA}

Junto a los ejes de evolución expuestos, cabe apuntar otra línea de desarrollo de la forma de gobierno local, que se refiere al arraigo y consolidación de los derechos de representación política de los electos locales con base en el derecho fundamental consagrado en el artículo 23.2 CE. A continuación, se da cuenta del modo en que se han modulado esos derechos, fundamentalmente en la jurisprudencia, pero también en la legislación; en concreto, se presta especial atención al caso de los concejales no adscritos. En este recorrido se mostrarán, sin carácter exhaustivo, algunas de las cuestiones más conflictivas a las que se ha tenido que enfrentar el legislador a la hora de determinar el estatuto de los electos locales. Todo ello sin perjuicio de los problemas que se han derivado del funcionamiento de los órganos colegiados locales (Colás Tenas, 2008: 76 ss.) y de la importancia que ha alcanzado en los últimos años la vertiente de la integridad y de la lucha contra la corrupción plasmada en la regulación del régimen de incompatibilidades, los conflictos de intereses y los códigos éticos orientados a garantizar el buen desempeño de sus cargos por los electos locales. Parece fuera de toda duda que este será un ámbito que continuará experimentando un importante desarrollo en el futuro.

\subsection{Acceso a la información}

La jurisprudencia ha puesto de manifiesto que en el funcionamiento cotidiano de los entes locales se producen numerosos conflictos con ocasión del ejercicio de los derechos de información y control por parte de los concejales. Con base en el artículo 77 LBRL todos los electos tienen derecho a obtener del alcalde y de la Junta de Gobierno Local -los órganos ejecutivos- los datos e informaciones que sean necesarios para desarrollar su función de control. Ese derecho se ha vinculado por la jurisprudencia con el núcleo del derecho fundamental de participación en los asuntos municipales. Entre otras muchas sentencias, la STS de 9 de diciembre de 1995 (6248/1995, ECLI:ES:TS:1995:6.248) insiste en que la negativa a facilitar a los concejales la información necesaria para ejercer su cargo lesiona el artículo $23 \mathrm{CE}$.

Ahora bien, los tribunales han distinguido entre el derecho de acceso a la información de los concejales y su derecho a obtener copias. El artículo 23.2 CE solo incluye el primero de estos derechos. El derecho a hacer copias en los casos del artículo 15 ROF deberá garantizarse cuando lo autorice el alcalde y, especialmente, cuando la información sea de acceso libre a los ciudadanos. No obstante, el ejercicio de ese derecho se somete a una ponderación en la que hay que contemplar el volumen de la documentación y la posible perturbación que su expedición o entrega pueda causar al funcionamiento de la entidad local, 
en función de los medios de que disponga. La carga de justificar y probar las circunstancias que motivan la denegación le corresponde al Ayuntamiento (por todas, la STS de 2 de julio de 2007, 4897/2007, ECLI:ES:TS:2007:4.897). Así, por ejemplo, en un supuesto en que la información se refiere al Presupuesto Municipal, que es un asunto a tratar en un órgano colegiado del Ayuntamiento, es de acceso libre y de carácter concreto, se vulnera el artículo 23.2 CE cuando se deniegan las copias (STS de 28 de enero de 2008, 900/2008, ECLI:ES:TS:2008:900).

\subsection{Derechos económicos}

En el ámbito de los derechos económicos de los electos locales se ha producido una importante evolución en los últimos cuarenta años. Antes de la LBRL solo se permitía que los alcaldes y presidentes de las Diputaciones provinciales percibieran asignaciones por el ejercicio del cargo. El resto de electos debían ejercer el cargo de forma gratuita. Solo podían percibir dietas por asistencia e indemnizaciones por gastos de representación. Esta situación cambió, sin embargo, de la mano de la Carta Europea de la Autonomía Local (art. 7.2) que exigía una compensación de los gastos o una remuneración del trabajo realizado con la cobertura social correspondiente (al respecto, en detalle, Rivero Ysern, 2014: 146). Por esa razón, la LBRL previo la posibilidad de que los electos con dedicación exclusiva percibieran una retribución (art. 75.1). Posteriormente, la Ley 1/1999 de reforma de la LBRL incluyó también la posibilidad de retribuir a los concejales que se encontraran en régimen de dedicación parcial.

En principio, el legislador no estableció límites concretos a estas retribuciones, que debían preverse en los presupuestos municipales. La crisis económica y los abusos cometidos en algunos municipios condujeron, sin embargo, a la fijación de determinados límites retributivos en la propia LBRL. La LRSAL incluyó un nuevo artículo 75 bis que contiene una tabla con límites retributivos en función de la población del municipio y tomando como referencia la retribución de los Secretarios de Estado. Asimismo, esta Ley marcó un límite al número de electos que pueden tener dedicación exclusiva, atendiendo también a la población del municipio (art. 75 ter).

En relación con las indemnizaciones, hay que mencionar que los electos locales tienen el deber de asistir a las sesiones de los órganos colegiados de los que son miembros. Con el fin de garantizar el cumplimiento de ese deber, el Presidente puede multar a aquellos concejales que no asistan a dichas sesiones sin justificación suficiente (art. 78.4 LBRL) en los términos que establezca la legislación autonómica o, en su caso, básica. Ahora bien, hay que tener en cuenta que el artículo 75 LBRL prevé que aquellos electos que perciben retribuciones fijas y periódicas no tienen derecho a percibir retribuciones por la asistencia a las sesiones de los órganos colegiados, lo que puede conducir a una pérdida de efecto de las multas señaladas, a no ser que se interprete que puede reducirse proporcionalmente la retribución del concejal que no asista a las sesiones convocadas (Alonso Higuera, 2017: 372).

\subsection{El estatuto de los concejales no adscritos}

Otra de las cuestiones que ha sido objeto de mayor desarrollo doctrinal y jurisprudencial en los últimos años ha sido la clarificación de los derechos que han de conformar el estatuto de los concejales no adscritos. La reforma de la LBRL, efectuada por la Ley 57/2003, de medidas para la modernización del gobierno local, introdujo la figura del representante no adscrito en el artículo 73.3 LBRL, que ya se había incluido en algunas legislaciones autonómicas (Alonso Mas, 2005: 96). De este modo se trataba de dar respuesta al fenómeno del transfuguismo en el ámbito municipal, pero también a las distintas circunstancias que podían derivar en la existencia de electos no adscritos: renuncia voluntaria, expulsión forzosa y la disolución y suspensión del grupo político (Nogueira Martínez, 2012: 67 ss.).

A lo largo de los años, la jurisprudencia tanto del Tribunal Constitucional como del Tribunal Supremo ha concretado los derechos que corresponden a este tipo de concejales: derechos económicos, derechos a participar en las comisiones informativas, etc. La STC 246/2012 consolida esa jurisprudencia y configura el estatuto de los concejales no adscritos en atención a tres grandes grupos de derechos: a) derechos ligados al núcleo de la función representativa de los concejales con base en el artículo $23.2 \mathrm{CE}$; b) derechos que no afectan a ese núcleo de la función representativa; c) y los derechos, tanto económicos como políticos, asociados únicamente a la adscripción de un concejal a un grupo político. Los primeros no se alteran en el caso de que el concejal tenga la condición de no adscrito, en la medida que el derecho de representación consagrado en el artículo 23.2 CE es un derecho individual. El resto puede modularse o suprimirse en el caso de los concejales no adscritos (De la Torre Martínez, 2014: págs. 115 ss.). 
El último de los hitos en relación con el reconocimiento de derechos a los concejales no adscritos es la STC 151/2017, que ha declarado la inconstitucionalidad del artículo 197.1 LOREG, en la medida en que establecía un quórum reforzado cuando entre los firmantes de una moción de censura hubiera concejales que hubieran dejado de pertenecer al grupo político del alcalde y que no estuvieran adscritos a ningún partido. El Tribunal Constitucional apoya su decisión en el hecho de que la participación en una moción de censura al alcalde constituye una parte nuclear del derecho de participación política consagrado en el artículo 23.2 CE. A su juicio, la decisión del legislador de establecer un quórum especial cuando la moción de censura se promueve por concejales no adscritos no supera un juicio de proporcionalidad. Se considera una medida idónea y necesaria para luchar contra el transfuguismo, pero no proporcionada, puesto que no diferencia entre las distintas circunstancias que pueden conducir a un concejal a abandonar su grupo político. La restricción uniforme del derecho a promover una moción de censura se declara, por ello, inconstitucional (en detalle, De la Torre Martínez, 2018: 119 ss.).

\section{RETOS DEL GOBIERNO LOCAL}

Tras la exposición de la evolución que han experimentado las formas de gobierno local en los últimos cuarenta años, parece oportuno identificar algunos de los retos que deberán afrontar las formas de gobierno local hacia el futuro. Algunos de estos retos son de carácter político y administrativo. Todos ellos se han manifestado ya en el pasado, sin que hayan sido resueltos, lo que hace sospechar que es posible que vuelvan a plantearse de nuevo. Además, son retos que también se han presentado en los países de nuestro entorno, de modo que las soluciones adoptadas pueden ser útiles para adoptar posibles decisiones de reforma del régimen local español. Es el caso de los problemas derivados de la profesionalización y separación de funciones entre decisiones políticas y técnicas en los Ayuntamientos; los gobiernos en minoría y el transfuguismo; así como la elección directa del Alcalde. Por otro lado, se abre un horizonte relacionado con los cambios a los que se están enfrentando ya en la actualidad nuestras sociedades y que suscitan problemas desde el punto de vista de las formas de gobierno. Así parece suceder en relación con la brecha existente entre los entornos rurales y urbanos, así como con el cambio de la demografía de los municipios que está vinculado al envejecimiento de la población. Ambos retos, relacionados con dos elementos esenciales de los municipios: territorio y población, respectivamente, pueden requerir una nueva reflexión sobre las formas de gobierno municipales. En seguida se desarrolla cada uno de estos retos brevemente.

\subsection{Retos políticos y administrativos}

\subsubsection{Profesionalización y separación de funciones}

El ánimo de democratización de los entes locales condujo en su momento a la atribución de competencias decisorias sobre la gestión municipal a los distintos órganos municipales. En el modelo establecido por la LBRL, son los electos locales los llamados a ejercer numerosas competencias de carácter administrativo, bien a título unipersonal (Alcalde) o de forma colegiada (Junta de Gobierno Local y Pleno). De modo que se implanta un sistema dicotómico entre política y función pública (Jiménez Asensio, 2011: 170), en el que el estrato político acumula las competencias para decidir en torno a cuestiones administrativas. Este modelo plantea problemas que pueden articularse en torno a dos tipos:

a) En primer lugar, parece innecesario hacer responsable del ejercicio de competencias técnicas a los electos locales, tanto en su condición de alcalde como de concejales. En determinadas decisiones donde la programación normativa requiere una interpretación técnica, ya sea técnico-jurídica o de otro tipo, no parece adecuado atribuir la competencia a los electos locales. Parece más razonable que esas competencias se atribuyan al personal municipal que goce de la capacitación profesional adecuada. Esto permitiría avanzar en el sentido de una profesionalización en el ámbito local y de la desaparición de algunas de las fricciones más importantes que se producen en el funcionamiento cotidiano de los entes locales, cuando se entrecruzan los criterios estratégicos, que han de ser eminentemente políticos, con criterios de gestión, que deben ser técnicos. En Italia, los reiterados casos de corrupción municipal condujeron al establecimiento de una separación clara entre las tareas de gestión administrativa, que se asignan a la Administración municipal-de modo que el Alcalde no es el órgano competente para la adopción de resoluciones concretas-; y las tareas de dirección y control político-administrativo, 
que se reparten entre los órganos integrados por los electos locales (Díez Sastre, 2010: 566). De modo que en un contexto de promoción de la integridad y de lucha contra la corrupción, podría convenir acometer algunas reformas orientadas a esta separación progresiva de funciones.

b) En segundo lugar, hay que dedicar un especial apartado a la atribución de capacidad decisoria al Pleno en cuestiones administrativas. Aunque esa situación trató de corregirse en el marco del proceso de «parlamentarización» del gobierno local, descrito más arriba, lo cierto es que aún existen decisiones administrativas que corresponden al Pleno y que dificultan la gestión municipal. El Pleno, como órgano colegiado integrado por los distintos grupos políticos y los concejales está diseñado para articular un debate fundamentalmente político. Su modo de funcionamiento se orienta precisamente a las tareas de elaboración normativa y de control; por eso no se adapta bien al ejercicio de competencias administrativas que exigen capacidad de dirección. Piénsese, por ejemplo, en los casos en que el Pleno es órgano de contratación y, conforme a la normativa de contratación pública, debería encargarse de la tramitación del procedimiento, desde la preparación del contrato hasta su adjudicación y posterior ejecución. No parece que el Pleno tenga una organización idónea para desempeñar de la mejor manera posible esas funciones. A estos obstáculos hay que sumar, además, que al atribuir funciones administrativas al Pleno puede producirse una paralización de la toma de ciertas decisiones cuando no existan mayorías suficientes. Esta cuestión se analiza en el siguiente punto.

Los problemas comentados, pueden llegar a justificar la necesidad de mejorar el reparto de funciones en el ámbito municipal. En este sentido, en un contexto de mejora de la gobernanza y de implantación de la «Nueva Gestión Pública», es necesario diversificar los roles dentro del gobierno local. Una fórmula para llevarlo a cabo puede ser el desarrollo de figuras como los directivos locales que pueden servir de enlace entre los políticos y los empleados públicos (a favor de esta opción, en detalle, Jiménez Asensio, 2011: 171 ss.). Asimismo, de forma complementaria, hay que tener en cuenta que el modelo de distribución competencial diseñado en la LBRL es un punto de partida que presenta variantes en la práctica a través de las técnicas de las delegaciones, lo que permite identificar en la práctica distintas formas de gobiernos locales que atienden a distintos factores. El estudio de la realidad parece en este sentido, ineludible, para afrontar posibles reformas normativas de la forma de gobierno local en el futuro (al respecto, en detalle, Pano Puey, 2017: 201 ss.).

\subsubsection{Gobiernos en minoría}

La progresiva fragmentación del mapa político en España ha intensificado los problemas que se producen en el gobierno local cuando existen gobiernos en minoría. Estas complicaciones se proyectan en distintas decisiones que se han identificado en la práctica (al respecto, en detalle, Alonso Higuera, 2016: 44 ss.): a) la creación de las comisiones informativas de carácter permanente en el Pleno; b) el diseño del sistema de delegaciones interorgánicas; c) el régimen de dedicación y retribución de los miembros electos, así como las características y número del personal eventual; d) el nombramiento de los miembros de los órganos de gobierno de los entes instrumentales, entre otros. En especial, llama la atención la determinación de la composición de los órganos de gobierno de los entes instrumentales. Una decisión de gestión de competencias municipales, que debería corresponder en exclusiva al ejecutivo municipal conforme al reparto legal de competencias entre los órganos municipales, acaba planteándose como un problema vinculado al Pleno y a los distintos grupos políticos (al respecto, de forma crítica, Velasco Caballero, 2019). Asimismo, se producen disfunciones cuando se prevén mayorías cualificadas para la toma de decisiones en el Pleno o cuando se reconoce el derecho de la oposición a la presentación de iniciativas o proposiciones que pueden llegar a sustituir al alcalde y a la Junta de Gobierno Local en su función de gobierno.

A la vista de estos problemas, cada vez más habituales en los municipios españoles, parece necesario buscar soluciones que puedan garantizar la gobernabilidad y estabilidad de los gobiernos locales. Una mayor profundización de la llamada «parlamentarización» del gobierno local puede ir en esa línea; pero también puede haber otras iniciativas como la elección directa del alcalde -que se aborda seguidamente- que pueden contribuir a garantizar el buen funcionamiento de los gobiernos locales.

\subsubsection{Elección directa del Alcalde}

El texto constitucional deja abierto el modo de elección del alcalde, de forma directa o indirecta. El artículo 140 señala que "[l]os Alcaldes serán elegidos por los Concejales o por los vecinos". El legislador 
orgánico determinó la elección del alcalde a través de los concejales. Una vez constituida la Corporación, tras la celebración de las elecciones municipales, se procede a elegir al alcalde de entre los concejales que encabecen sus correspondientes listas. Se proclama electo a quien obtenga la mayoría absoluta de los votos de los concejales. De no existir mayoría absoluta, será proclamado alcalde quien encabece la lista que haya obtenido mayor número de votos. De existir empate, se resolverá por sorteo. En el caso de los municipios de entre 100 y 250 habitantes, pueden ser alcalde todos los concejales. Será elegido quien tenga mayoría absoluta de los votos de los concejales, si no, se proclamará alcalde a quien obtenga más votos populares en las elecciones de concejales (art. 196 LOREG).

A pesar de la consolidación de esta forma de elección del alcalde, desde hace más de veinte años se abre de forma intermitente el debate sobre la introducción de un sistema de elección directa, esto es, de elección a través de los vecinos. Y lo más llamativo es que esa posibilidad se ha defendido por partidos, en principio, antagónicos. El Partido Socialista presentó en 1998 una proposición de reforma de la LOREG para que se eligiera directamente al alcalde. De hecho, la reforma de la LBRL acometida por la Ley 57/2003, de 16 de diciembre, de medidas para la modernización del gobierno local, se consideró un paso necesario para introducir la elección directa del alcalde (Díez Sastre, 2004: 233). Posteriormente, en 2014, el Partido Popular declaró su voluntad de implantar este sistema, aunque, en realidad, se decantaba por establecer un modelo de bonus de mayoría, a la lista más votada, como sucede en Francia o Italia (Simón, 2014). En el ínterin, el Consejo de Estado emitió un Informe (de 24 de febrero de 2009), en el que se estudiaban las posibilidades y alternativas de modificación del sistema electoral, incluido el régimen electoral a nivel local (García, 2011: 206).

Ninguna de estas propuestas tuvo éxito, sin embargo, en la doctrina se sigue planteando la posibilidad de introducir esta forma de elección (Salazar Benítez, 2007: 154 ss.; más recientemente, Font i Llovet y Galán Galán, 2014: 24 ss.). Con ello se busca reforzar la legitimidad de los gobiernos locales (Ridao i Martín, García y Martínez, 2015: 84), mejorando la calidad democrática del gobierno local, así como garantizar estabilidad y gobernabilidad de los Ayuntamientos en el contexto de mayor fragmentación política al que se ha aludido más arriba (García, 2011: 216 ss.; Arenilla Sáez, 2015; Navarro Gómez y Sweeting, 2015: 108). A pesar de estas posibles bondades, no hay que perder de vista que la elección directa supone sobre todo un reto para los partidos políticos que pueden perder su influencia en la política local. No en vano, en los países en que se ha introducido esta forma de elección, un importante porcentaje de los alcaldes no está afiliado a ningún partido, con las consecuencias que ello tiene desde el punto de vista político (al respecto, en detalle, Navarro Gómez y Sweeting, 2015: 111 ss.). Esta circunstancia puede suponer un obstáculo importante en la introducción de esta forma de elección de los alcaldes.

Más allá del análisis de ventajas y desventajas del modelo, lo cierto es que la introducción de la elección directa del alcalde exige una reflexión global sobre la forma de gobierno a nivel local, que va más allá de las fórmulas electorales. En concreto, el cambio en la forma de elección del alcalde requiere un análisis sobre el reparto de poder entre los órganos municipales y las relaciones existentes entre ellos. Específicamente, obliga a reflexionar sobre los mecanismos de control del Alcalde por el Pleno, ya que la moción de censura y la cuestión de confianza no se ajustan bien a un modelo de alcaldes elegidos directamente por los vecinos (García, 2011: 226 ss.). Esto es lo que muestra la experiencia de los países de nuestro entorno que, en su momento, introdujeron esta forma de elección del alcalde (al respecto, Bertrana Horta y Magre Ferrán, 2017) y de otros países como Canadá, Japón o Estados Unidos, que cuenta con una larga tradición de elección directa de los alcaldes (Navarro Gómez y Sweeting, 2015: 106). Valgan como prueba los siguientes ejemplos:

a) En el caso de Alemania, solo los Länder del sur elegían directamente a los alcaldes (Baviera y Baden-Württemberg), pero en la década de los noventa del siglo pasado -tras la Reunificación- este modo de elección del alcalde se extendió por todo el territorio como un modo de mejorar la participación ciudadana en el nivel local de gobierno y de fomentar el principio democrático (Díez Sastre, 2004: 242 ss.). La elección directa del alcalde se acompañó de un reforzamiento de su posición en el gobierno, pero también de la introducción de más controles sobre el ejecutivo. Con este fin se introdujo la posibilidad de revocar el nombramiento del alcalde (Abwahl), bien a propuesta del Alcalde o de los ciudadanos, según los casos.

b) En Italia, la elección directa del alcalde se introdujo de forma simultánea a Alemania, aunque se explica por razones distintas, como reacción a la crisis de los partidos derivada de los escándalos vinculados a la corrupción a principios de los noventa. El sistema se consolidó, favoreciendo el gobierno de la lista más votada con un premio o bonus de mayoría en las regiones ordinarias y manteniendo 
la posibilidad de introducir variantes en el sistema electoral en las regiones especiales. Ahora bien, se conservaron tanto la moción de censura del alcalde por el pleno, como la disolución del Pleno en caso de dimisión del alcalde (Medina Alcoz, 2010: 236; en detalle, sobre el modelo inicial, Beltrán de Felipe, 1993).

c) Por último, en el Reino Unido, la elección directa se implantó solo en Inglaterra y Gales, pero de forma optativa. En Irlanda del Norte y Escocia se mantuvo un modelo de elección por los miembros de la Asamblea. La posibilidad de introducir la elección directa fracasó en la mayoría de los casos, donde se mantuvo el sistema de elección indirecta, lo que puede relacionarse con los bajos niveles de autonomía local garantizados en el Reino Unido, a diferencia de los países en Europa continental (Díez Sastre, 2010: 562).

\subsection{Retos geográficos y demográficos}

\subsubsection{Eje rural-urbano}

Junto a los retos de carácter político y administrativo, parece importante atender a la realidad, cada vez más visible, de las diferencias existentes entro los gobiernos locales que se encuentran en entornos rurales y urbanos, respectivamente. En España, la entrada en el siglo XXI ha venido acompañada de un importante incremento de la movilidad de la población tanto dentro del territorio como hacia el exterior. Por lo que respecta a la movilidad interior, está orientada, fundamentalmente, hacia las grandes ciudades, que incrementan su población a costa de los pequeños municipios y de las capitales de provincia de menor tamaño. En consecuencia, se produce un efecto de metropolización de determinadas ciudades, cuyos ejemplos paradigmáticos son Madrid y Barcelona. En la figura que se presenta a continuación puede verse la serie de los últimos diez años de recepción de población por provincias.

Figura 1. Diez provincias con mayor aUmento de población en los Últimos diez AÑos (2008-2018) [AUMENTO EN NÚMERO DE HABITANTES]

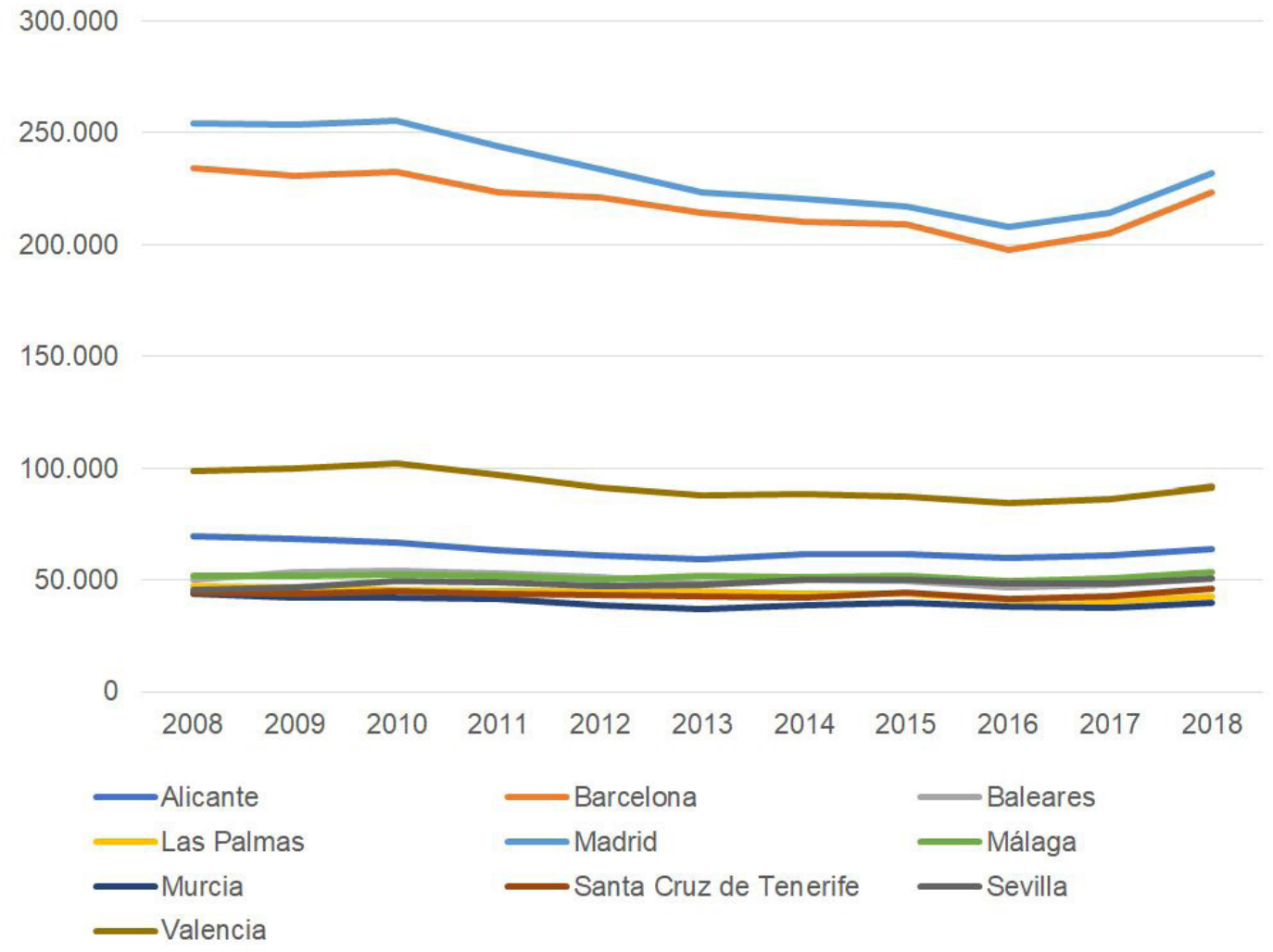

Fuente: elaboración propia a partir de datos del INE. 
De los datos mostrados se colige con facilidad que los mayores incrementos de población se producen en aquellas provincias que cuentan con una gran ciudad que sirve como polo de atracción económico, laboral y cultural. Dicho en otras palabras, las capitales de provincia de menor tamaño y, sobre todo, los municipios de pequeño tamaño que se encuentran en el ámbito rural, experimentan un menor incremento de población e, incluso, una rebaja del número de habitantes. Este progresivo desplazamiento de población del ámbito rural a los entornos urbanos produce alteraciones importantes en la configuración de los municipios. En la Tabla que se presenta a continuación se observa una tendencia consolidada al crecimiento del número de municipios con una población cada vez más baja.

TABLA 1. EVOLUCIÓN DEL NÚMERO DE MUNICIPIOS EN FUNCIÓN DE SU POBLACIÓN (1979-2011) [EN NÚMERO Y PORCENTAJE]

\begin{tabular}{|c|c|c|c|c|c|}
\hline Habitantes & 1979 & 2011 & \multicolumn{3}{|c|}{ Diferencia (núm. - \%) } \\
\hline Hasta 250 & 1.855 & 2.609 & 754 & - & $40 \%$ \\
\hline $251-5.000$ & 4.933 & 4.160 & -773 & - & $-15 \%$ \\
\hline $5.001-20.000$ & 825 & 918 & 93 & - & $11,2 \%$ \\
\hline $20.001-50.000$ & 162 & 252 & 90 & - & $55 \%$ \\
\hline $50.001-300.000$ & 86 & 132 & 46 & - & $53 \%$ \\
\hline Más 300.000 & 9 & 13 & 4 & - & $44 \%$ \\
\hline ESPAÑA & 7.870 & 8.084 & 214 & - & $2,7 \%$ \\
\hline
\end{tabular}

Fuente: elaboración propia a partir del Informe “Elecciones municipales en España 1979-2011”, Ministerio del Interior, 2014.

En esta situación se plantean numerosos retos a los gobiernos locales y, en concreto, a la forma de gobierno local, que pueden ordenarse en torno a dos ideas, la consolidación de ciudades globales y la despoblación del espacio rural:

a) Por un lado, las grandes ciudades que están experimentando un mayor incremento de población reclaman un espacio distinto en la arena política, dentro del sistema territorial, así como un régimen jurídico diferenciado. En el caso de Madrid y Barcelona ya se ha expuesto cómo su singularidad motivó la elaboración de regímenes de Carta. Ahora bien, es posible que en el futuro haya que desarrollar aún más esas particularidades jurídicas que reflejan un fenómeno contemporáneo que parece inevitable: la aparición de ciudades globales que reivindican un espacio propio no solo a nivel nacional, sino también internacional (al respecto, en detalle, Velasco Caballero, 2018: págs. 28 ss.; González Medina, 2019: 199 ss.).

b) Por otro lado, la despoblación del mundo rural conduce a la multiplicación de municipios con un escaso volumen de población. Una de las reacciones directas del legislador a esta realidad ha sido la fijación de un umbral mínimo de 5.000 habitantes para crear nuevos municipios, a partir de la reforma de la LBRL (art. 13.2) por la LRSAL. Esta medida es fruto del debate abierto en torno a la posible reducción de municipios de pequeño tamaño en los tiempos de la crisis económica (Rebollo Puig, 2008), que finalmente fracasó tratando de reformar el mapa municipal (Carbonell Porras, 2018: 6 ss.). No obstante, su finalidad es garantizar la sostenibilidad financiera de los nuevos municipios en el marco de las competencias del Estado (STC 41/2016) (Pons-Portella, 2016: 113 ss.). Pues bien, sin perjuicio de la oportunidad de esta medida, es necesario prestar mayor atención a este fenómeno, que tiene un claro impacto en la prestación de servicios, pero también en la forma de gobierno de los municipios. Ya se ha señalado que la regulación del gobierno local en la LBRL ha tendido tradicionalmente a una cierta homogeneización, dando un espacio relativo al desarrollo autonómico, que pueda ser más sensible a las diferencias geográficas, demográficas, económicas, sociales e, incluso, culturales. Quizás, en el futuro, sea necesario diversificar de una forma más clara las formas de gobierno local y la propia estructura territorial de los municipios con el fin de atender a los problemas que se están manifestando en el siglo XXI. 


\subsubsection{Envejecimiento de la población}

De forma complementaria a los retos que se derivan de la distinción entre entornos urbanos y geográficos habría que situar también el envejecimiento de la población. En 2014, el $20 \%$ de la población de ciudades de más de 500.000 habitantes superaba los 65 años. Estos datos son todavía más llamativos en el ámbito rural, que concentra un porcentaje mayor de población envejecida. Ello se explica, entre otros factores, por la continuada emigración de su población desde la segunda mitad del siglo XX (Elizalde-San Miguel, 2018). En 2016, el porcentaje de población mayor a 65 años en municipios de menos de 5.000 habitantes era del $24,4 \%$, frente al $18,6 \%$ del resto de municipios; en el mismo sentido, los vecinos mayores de 80 años en los municipios de menos de 5.000 habitantes representaban el 9,2\% de la población frente al 5,9\% de los municipios de mayor tamaño (Elizalde-San Miguel, 2018). Atendiendo a una información desagregada, hay que tener en cuenta que, en 2014, los vecinos de más de 65 años representaban el $32 \%$ de la población en municipios de entre 101 y 500 habitantes; el $27 \%$ en municipios de entre 501 y 1.000 habitantes; y el $25 \%$ en municipios de entre 1.001 y 2.000 habitantes (datos elaborados a partir del trabajo de Abellán García et alia, 2015).

El envejecimiento de la población, especialmente en el ámbito rural, pero también en el ámbito urbano, no solo supone un reto para la prestación de servicios municipales, sino que también puede plantear problemas desde el punto de vista de la viabilidad de las formas de gobierno previstas en los pequeños municipios. Los gobiernos locales requieren la participación de los vecinos de forma activa, en primera instancia, como electores y, en segunda instancia, como concejales o alcaldes (arts. 184 y 196 LOREG). Esta necesidad se acentúa en los casos de las fórmulas de gobierno que descansan en la democracia directa. El envejecimiento de la población puede dificultar esa participación. En este sentido, la reforma de la LOREG, a través de la Ley Orgánica 2/2011, de 28 de enero, ha supuesto una reducción del número de municipios que se rigen por el sistema de concejo abierto, con el fin de facilitar su funcionamiento en los casos en que los vecinos no están en condiciones o no tienen incentivos para participar en la política local (Salanova Alcalde, 2011: 19).

Al mismo tiempo, hay que tener en cuenta que es fundamental para el bienestar de las personas mayores fomentar la participación en su entorno (Monreal Bosch, 2009). De modo que uno de los retos de los gobiernos locales en el futuro será lograr involucrar a las personas mayores en la política municipal, a través de órganos de participación como los consejos de personas mayores y de nuevas iniciativas que permitan conocer sus necesidades y mejorar las formas de satisfacerlas.

\section{REFERENCIAS BIBLIOGRÁFICAS}

ABELLÁN GARCÍA, A.; PUJOL RODRÍGUEZ, R.; RAMIRO FARIÑAS, D.; y PÉREZ dÍAZ, J. (2015): "Pirámide rural", en Blog envejecimiento en red. CSIC. Disponible en línea: http://envejecimiento.csic.es/documentos/blog/ Piramide-rural.pdf.

ALMEIDA CERREDA, M. (2015): "Tres procesos contemporáneos de reforma de las organizaciones administrativas locales: orígenes, finalidades y líneas de actuación coincidentes”, en ALMEIDA CERREDA, M.; TUBERTINI, C. y GONÇALVES, P. (dirs.): La racionalización de la organización administrativa local: las experiencias española, italiana y portuguesa, págs. 29-44. Cizur Menor: Civitas.

ALONSO HIGUERA, C. (2016): "Gobernar en minoría ayuntamientos fragmentados", en Cuadernos de Derecho Local, núm. 40, págs. 37-67.

ALONSO HIGUERA, C. (2017): "El Estatuto de los electos locales", en Revista Vasca de Administración Pública, núm. 107-II, págs. 367-470.

ALONSO MAS, M. J. (2005): “El discutible régimen jurídico de los concejales no adscritos”, en RAP, núm. 168, págs. 95-130.

ARENILLA SÁEZ, M. (coord.) (2015): La elección directa del alcalde. Reflexiones, efectos y alternativas. Barcelona: Fundación Democracia y Gobierno Local.

BARRERO RODRÍGUEZ, C. (2017): "La situación actual de las diputaciones: Los extremos esenciales de un debate por resolver", en PAREJO ALFONSO, L. J. (dir.): El futuro de la Administración local y el papel de los gobiernos locales intermedios, págs. 315-360. Madrid: Fundación Democracia y Gobierno Local.

BELTRÁN DE FELIPE, M. (1993): "La nueva Ley electoral local italiana (Ley de 25 de marzo de 1993, n. ${ }^{\circ} 81$, de elección directa de los alcaldes y presidentes provinciales)", en REALA, núm. 259, págs. 583-600. DOI: https://doi. org/10.24965/reala.vi259.8793.

BERTRANA HORTA, X. y MAGRE FERRÁN, J. (2017): "Elección directa del alcalde y cambio institucional: una aproximación comparada”, en Anuario del Gobierno Local 2017, págs. 131-154. 
CALDERÓ CABRÉ, A. (1998): "Modelos de gobierno municipal”, en CASTILLO BLANCO, F. (coord.): Estudios sobre los gobiernos locales, págs. 1-43. Granada: CEMCl.

CARBONELL PORRAS, E. (2009): "Los municipios de gran población, cinco años después”, en Revista General de Derecho Administrativo, núm. 20.

CARBONELL PORRAS, E. (2018): "La alteración de términos municipales en la reforma de 2013: crónica de un fracaso anunciado", en REALA, Nueva Época, núm. 9, págs. 5-21. DOI: https://doi.org/10.24965/reala.v0i9.10513.

CASES PALLARÉS, J. (2008): "La organización municipal en el régimen especial de la Carta Municipal de Barcelona”, en BETANCOR RODRÍGUEZ, A. y NOGUERA DE LA MUELA, B.: Comentarios al régimen municipal especial de Barcelona, págs. 81-117. Cizur Menor: Thomson Reuters Aranzadi.

COLÁS TENAS, J. (2008): "El funcionamiento de los órganos colegiados de las entidades locales: las sesiones", en Cuadernos de Derecho Local, núm. 18, págs. 75-109.

COSCULLUELA MONTANER, L. (2011): "El debate sobre la abolición de la provincia y la reforma de las diputaciones", en Anuario del Gobierno Local 2011, págs. 45-67.

DE LA TORRE MARTÍNEZ, L. (2014): El estatuto jurídico de los concejales no adscritos. Madrid: Fundación Democracia y Gobierno Local.

DE LA TORRE MARTíNEZ, L. (2017): "De nuevo sobre los concejales no adscritos (a propósito de la sentencia del tribunal constitucional 151/2017, de 21 de diciembre)", en REALA Nueva Época, núm. 9, págs. 110-127. DOI: https://doi.org/10.24965/reala.v0i9.10511.

DíEZ SASTRE, S. (2004): "La elección directa del alcalde en Alemania", en Anuario del Gobierno Local 2004, págs. 233-253.

DÍEZ SASTRE, S. (2010): "Planta local y régimen municipal”, en VELASCO CABALLERO, F. (dir.); DÍEZ SASTRE, S.; GALÁN GALÁN, A. y RODRÍGUEZ DE SANTIAGO, J. M. (coords.): Gobiernos locales en Estados federales y descentralizados: Alemania, Italia y Reino Unido, págs. 547-575. Barcelona: Generalitat de Catalunya, Institut d'Estudis Autonòmics.

EMBID IRUJO, A. (1981): "Autonomía municipal y Constitución: aproximación al concepto y significado de la declaración constitucional de autonomía municipal”, en REDA, núm. 30, págs. 437-470.

ELIZALDE-SAN MIGUEL, B. (2018): "El envejecimiento en el mundo rural, ¿una oportunidad para cambiar las relaciones de género?”, en Observatorio Social La Caixa. Disponible en línea: https://observatoriosociallacaixa. org/-/el-envejecimiento-en-el-mundo-rural.

FERNÁNDEZ FARRERES, G. (2011): "La potestad local de autoorganización: contenido y límites", en MUÑOZ MACHADO, S. (dir.): Tratado de Derecho Municipal, Tomo II, págs. 1.467-1.494. 3. ${ }^{a}$ edición.

FONT I LLOVET, T. (2002): "Reforma básica y desarrollo del gobierno local: entre Estado y comunidades Autónomas", en Anuario del Gobierno Local 2002, págs. 13-35.

FONT I LLOVET, T. (2005): "Estado autonómico y gobierno local en el inicio de un nuevo ciclo", en Anuario de Gobierno Local 2005, págs. 13-26.

FONT I LLOVET, T. (2006): El régimen local en la reforma de los Estatutos de Autonomía. Madrid: FORO/CEPC.

FONT I LLOVET, T. y GALÁN GALÁN, A. (2014): "Los retos actuales del Gobierno local: repolitización, diversificación e interiorización", en Anuario del Gobierno Local 2014, págs. 11-42.

FUERTES, M. (1991), "Los órganos municipales de carácter complementario" en Documentación Administrativa, núm. 228, págs. 167-186. DOI: https://doi.org/10.24965/da.v0i228.5261.

GALÁN GALÁN, A. (2010): "El reparto del poder sobre los Gobiernos locales: Estatuto de Autonomía, Tribunal Constitucional e interiorización autonómica del régimen local”, en Anuario del Gobierno Local 2010, págs. 97-159.

GARCíA, M. J. (2011): "La elección directa del alcalde en el régimen local: justificación, alcance y repercusiones", en REDC, núm. 91, págs. 205-258.

GONZÁLEZ MEDINA, M. (2019): "El poder de las ciudades globales: análisis comparado de cuatro ciudades iberoamericanas", en Anuario de Derecho Municipal 2018, núm. 12, págs. 195-218.

JIMÉNEZ ASENSIO, R. (2003): "Política y administración en la reforma del gobierno local (un estudio sobre la forma de gobierno y la alta administración en los «municipios de gran población»)", en Anuario del Gobierno Local 2003, págs. 71-106.

JIMÉNEZ ASENSIO, R. (2011): "Sobre las dificultades (fáctico-normativas) de implantación de la dirección pública profesional en los gobiernos locales”, en Anuario de Derecho Municipal 2010, págs. 167-194.

MEDINA ALCOZ, LUIS (2010): "Italia" (epígrafes I, aps. 5.1.2, 5.2 y 6, II y IV), en VELASCO CABALLERO, F. (dir.); DÍEZ SASTRE, S.; GALÁN GALÁN, A. y RODRÍGUEZ DE SANTIAGO, J. M. (coords.): Gobiernos locales en Estados federales y descentralizados: Alemania, Italia y Reino Unido. Barcelona: Generalitat de Catalunya, Institut d'Estudis Autonòmics.

MONREAL BOSCH, P.; DEL VALLE GÓMEZ, A. y SERDA FERRER, B. (2009): "Los grandes olvidados: las personas mayores en el entorno rural”, en Psychosocial Intervention, vol. 8, núm. 3. Disponible en línea: http:// scielo.isciii.es/scielo.php?script=sci_arttext\&pid=S1132-05592009000300007. DOI: https://doi.org/10.5093/ in2009v18n3a7.

MORELL OCAÑA, L. (2011): "Las provincias", en MUÑOZ MACHADO, S. (dir.), Tratado de Derecho Municipal, Tomo I, págs. 1.563-1.598. Madrid: Iustel. 3. ${ }^{a}$ edición. 
NAVARRO GÓMEZ, C. y SWEETING, D. (2015): "La elección directa de los alcaldes. Características, experiencias comparadas y el singular caso de los alcaldes quasi-directamente elegidos españoles", en Anuario de Derecho Municipal 2014, págs. 106-126.

NOGUEIRA MARTÍNEZ, D. (2012): "El ámbito de aplicación del estatuto legal de los representantes locales no adscritos", en Anuario de Derecho Municipal 2011, núm. 5, págs. 63-96.

PARADA VÁZQUEZ, J. R. (2007): “La segunda descentralización: del Estado autonómico al municipal”, en RAP, núm. 172, págs. 9-77.

PAREJO ALFONSO, L. (1991): “La potestad de autoorganización de la Administración Local”, en Documentación Administrativa, núm. 228, págs. 13-43. DOI: https://doi.org/10.24965/da.v0i228.5255.

PAREJO ALFONSO, L. (2011): “La autonomía local en la Constitución española”, en MUÑOZ MACHADO, S. (dir.), Tratado de Derecho Municipal, Tomo I, págs. 47-210. Madrid: Iustel. 3. ${ }^{a}$ edición.

PAREJO ALFONSO, L. (2014): "Algunas reflexiones sobre el impacto de la Ley 27/2013, de 27 de diciembre, sobre el modelo de autogobierno municipal”, en Cuadernos de Derecho Local, núm. 34, págs. 11-20.

ORTEGA ÁLVAREZ, L. (2011a): "El régimen local en los nuevos Estatutos de Autonomía", en MUÑOZ MACHADO, S. (dir.): Tratado de Derecho Municipal, Tomo I, págs. 253-285. Madrid: lustel. 3. a edición.

ORTEGA ÁLVAREZ, L. (2011b): "Las relaciones de control entre órganos municipales", en MUÑOZ MACHADO, S. (dir.): Tratado de Derecho Municipal, Tomo I, págs. 903-921. Madrid: Iustel. 3. ${ }^{a}$ edición.

ORTEGA ÁlVAREZ, L. (2011c): "Régimen especial de cartas", en MUÑOZ MACHADO, S. (dir.): Tratado de Derecho Municipal, Tomo I, págs. 1.615-1.642. Madrid: lustel. 3. ${ }^{a}$ edición.

PANO PUEY, E. (2017): Homogeneïtat i heterogeneïtat en la forma de govern municipal. Tesis doctoral, Universidad de Barcelona. Disponible en línea: $h t t p s: / / w w w . t d x . c a t / h a n d l e / 10803 / 663731 \# p a g e=1$.

POMED SÁNCHEZ, L. (2010): "El régimen local de Cataluña tras la STC 31/2010: interiorización en los términos de la Constitución", en Anuario del Gobierno Local 2010, págs. 69-95.

PONS-PORTELLA, M. (2016): "La población mínima de los nuevos municipios: estado de la cuestión tras la Ley de Racionalización y Sostenibilidad de la Administración Local”, en REALA Nueva Época, núm. 5, págs. $106-119$. DOI: https://doi.org/10.24965/reala.v0i5.10353.

REBOLLO PUIG, M. (2008): "La supresión de los pequeños municipios: régimen, alternativas, ventajas e inconvenientes", en REALA, núm. 308, págs. 151-206. DOI: https://doi.org/10.24965/reala.v0i308.9701.

RIDAO I MARTÍN, J. y GARCÍA I MARTÍNEZ, A. (2015): "La elección directa del alcalde por los vecinos. Criterios para un régimen presidencialista en los gobiernos municipales”, en REALA Nueva Época, núm. 3, págs. 77-93. DOI: $h$ ttps://doi.org/10.24965/reala.v0i3.10241.

RIVERO-YSERN, J. L. (2014): Manual de Derecho Local. Cizur Menor: Civitas. 7. ${ }^{a}$ edición.

SALANOVA ALCALDE, R. (2011): Manual sobre organización y funcionamiento de los municipios. Cizur Menor: Civitas.

SALAZAR BENÍTEZ, O. (2007): El sistema de gobierno municipal. Madrid: CEPC.

SÁNCHEZ MORÓN, M. (2011): "La distribución de competencias entre el Estado y las Comunidades Autónomas en materia de régimen local”, en MUÑOZ MACHADO, S. (dir.): Tratado de Derecho Municipal, Tomo I, págs. 337389. Madrid: lustel. $3 .^{a}$ edición.

SANTAMARÍA PASTOR, J. A. (1982): "Notas sobre la sentencia de las Diputaciones provinciales", en Revista Española de Derecho Constitucional, núm. 34, págs. 179-208.

SIMÓN, P. (2014): "La elección directa de los alcaldes", 3 de julio de 2014, en Politikon. Disponible en línea: https:// politikon.es/2014/07/03/la-eleccion-directa-de-los-alcaldes/.

TAJADURA TEJADA, J. (2019): "El futuro de las provincias y las diputaciones provinciales ante una reforma de la Constitución territorial”, en Teoría y Realidad Constitucional, núm. 43, págs. 229-256. DOI: https://doi.org/10.5944/ trc.43.2019.24409.

VELASCO CABALLERO, F. y DÍEZ SASTRE, S. (2008): "Sobre la forma de gobierno de Barcelona: régimen jurídico de las resoluciones administrativas del Consejo Municipal”, en Cuadernos de Derecho Local, núm. 17, págs. 4969. Disponible en línea: $h$ ttp://hdl.handle.net/10873/369.

VELASCO CABALLERO, F. (2009): Derecho local. Sistema de fuentes. Madrid: Marcial Pons.

VELASCO CABALLERO, F. (2018): "El Derecho de las ciudades globales", en Anuario de Derecho Municipal 2017, núm. 11, págs. 23-40.

VELASCO CABALLERO, F. (2019): “El sistema del gobierno local”, en Anuario del Gobierno Local 2019. 